\title{
Influência do NaClO na germinação de sementes de alface em Parnaíba-PI
}

\section{Influence of NaClO on lettuce seed germination in Parnaíba-PI}

\author{
Mauro Sergio Teodoro ${ }^{1}$; Maria da Conceição Sampaio Alves ${ }^{2}$; Francisco José dos Santos Seixas ${ }^{3}$; Mairla Nascimento de \\ Lacerda $^{4}$; Luma Melisa da Silva Araújo ${ }^{4}$
}

Resumo: O presente trabalho foi desenvolvido em condições de casa de vegetação situada em Parnaíba-PI, município onde predominam altas temperaturas. Objetivou-se avaliar a germinação de diferentes lotes de sementes de alface antes e após a embebição em solução de hipoclorito de sódio ( $\mathrm{NaCIO})$. O delineamento experimental foi em blocos casualisados, com os tratamentos dispostos em arranjo fatorial 2 × 7 (duas variáveis como pré-germinativos: com imersão em $\mathrm{NaClO}$ e sem imersão em $\mathrm{NaClO}$, e sete cultivares de alface), com quatro repetições. As variáveis analisadas foram: Primeira contagem do teste de germinação (PCG), Teste de germinação (TG) e Índice de velocidade de germinação (IVG). Analisando-se os dados obtidos, verificou-se que independente da presença ou ausência do tratamento pré-germinativo, a cultivar T6 foi a que apresentou os melhores resultados para as variáveis analisadas. Exceto T2, todas as outras cultivares que receberam tratamento com hipoclorito de sódio $(\mathrm{NaClO})$ obtiveram resultados expressivos, em comparação com as que não receberam esse tratamento, entretanto, a germinação de todos os lotes foi inferior ao estabelecido para comercialização de sementes de alface, com recomendações acima de $80 \%$.

Palavras-chaves: condições ambientais, termo dormência, escarificação

Abstract: The present study aimed to evaluate, under conditions of a greenhouse located in Parnaiba, PI, where high temperatures and after soaking in solution of sodium hypochlorite ( $\mathrm{NaCIO}$ ), the germination of seeds of seven cultivars of lettuce. The experimental design was of randomized blocks, with treatments arranged in factorial arrangement $2 \times 7$ (two variables as pré-germinativos: with $\mathrm{NaClO}$ and immersion without immersion in $\mathrm{NaClO}$, and seven cultivars of lettuce), with four replicates. The seeds were subjected to the following determinations: First germination test score (PCG), germination test (TG) and germination speed Index (IVG). Analyzing the data obtained, it was found that regardless of the presence or absence of treatment pre-germinative, cultivating T6 was presented the best results for the variables analyzed. Except for T2, all other cultivars that received treatment with sodium hypochlorite $(\mathrm{NaClO})$ achieved significant results, compared to those who did not receive this treatment, however, the germination of all batches was lower than that established for commercialization of seeds of lettuce, with recommendations above 80 .

Key words: environmentalconditions, termodormência, scarification

\footnotetext{
*Autor para correspondência

Recebido para publicação em 19/05/2015; aprovado em 28/09/2015

${ }^{1}$ Analista; Embrapa Meio-Norte; BR 343, Km 35, caixa postal 341, Parnaíba-PI, CEP 64200-970; mauro-sergio.teodoro@embrapa.br

${ }^{2}$ Professor; Universidade Estadual do Piauí - UESPI, Campus Professor Alexandre Alves de Oliveira, Av. Nossa Senhora de Fátima, S/N, Parnaíba-PI, CEP 64202-220; mariateixeira277@gmail.com

${ }^{3}$ Pesquisador; Embrapa Meio-Norte; BR 343, Km 35, caixa postal 341, Parnaíba-PI, CEP 64200-970; francisco.seixas@embrapa.br

${ }^{4}$ Estudante; Universidade Estadual do Piauí - UESPI, Campus Professor Alexandre Alves de Oliveira, Av. Nossa Senhora de Fátima, S/N, Parnaíba-PI, CEP 64202-220; mairllaphb@hotmail.com, lumamelisa@hotmail.com
} 


\section{INTRODUÇÃO}

Alface (Lactuca sativa L.) é uma importante hortaliça folhosa cultivada em várias partes do mundo. A evolução de cultivares e sistemas de manejo, tratos culturais, irrigação, espaçamentos, técnicas de colheita e de conservação pós-colheita e mudanças nos hábitos de alimentação impulsionaram o seu cultivo (RESENDE et al., 2007), sendo considerada uma das olerícolas de maior volume de comercialização, ocupando a quinta posição entre as hortaliças produzidas no Brasil (MINISTÉRIO DA AGRICULTURA, 2011).

Proveniente de clima temperado, a adaptação da alface a locais de temperatura e luminosidade elevada tem gerado obstáculos no seu crescimento impedindo que ela expresse todo seu potencial genético (SETUBAL e SILVA, 1992). No Nordeste brasileiro, o cultivo desta hortaliça restringe-se a pequenas áreas, com a utilização de cultivares pouco adaptadas às condições climáticas da região (QUEIROGA et al., 2001). De acordo com os autores, dentre os fatores que estão associados à baixa produção, destacam-se a falta de assistência técnica e a falta de difusão de tecnologias que melhorem o manejo cultural desta olerícola.

Embora o melhoramento genético dessa espécie tenha proporcionado bons resultados, colocando à disposição dos produtores várias cultivares adaptadas para o plantio em cada época do ano, é indispensável avaliá-las em diferentes locais, pois o comportamento biológico e produtivo da alface é influenciado pelas condições edafoclimáticas (SILVA e VIZZOTO, 1994).

A propagação da alface se dá por meio de sementes, as quais apresentam particular sensibilidade às variações na umidade e temperatura do meio onde germinam (BERTAGNOLLI et al., 2003).

A identificação de genótipos termotolerantes é importante, uma vez que torna adequada à produção da alface a uma maior amplitude de regiões e épocas do ano. De acordo com FILGUEIRA (2003), das sementes de alface, a germinação, a emergência e o desenvolvimento inicial de plântulas são diretamente afetados pela temperatura do substrato no qual se efetua a semeadura. De acordo com o autor, a temperatura ótima para semeadura é em torno de $20^{\circ} \mathrm{C}$ e a maioria das cultivares não germinam em temperaturas superiores a $30^{\circ} \mathrm{C}$.

Quando as temperaturas variam de 10 a $20^{\circ} \mathrm{C}$ a porcentagem de germinação de sementes de alface são superiores a $80 \%$ e, em temperaturas superiores a $30^{\circ} \mathrm{C}$, essas sementes entram em estado de dormência, onde elas não voltam a germinar, mesmo em temperaturas adequadas (MARCOS FILHO, 2005; NASCIMENTO e PEREIRA, 2007).

No Brasil, temperaturas acima de $30^{\circ} \mathrm{C}$ são facilmente encontradas no verão em muitas regiões do país. Dados meteorológicos diários referentes ao mês de julho de 2013, época de realização deste ensaio em Parnaíba, Piauí, registraram uma média máxima de até $35,3^{\circ} \mathrm{C}$.

Vários métodos para reduzir o problema da termoinibição têm sido propostos, incluindo a utilização de germoplasmas tolerantes, ajuste do ambiente de produção de sementes, utilização de reguladores vegetais e condicionamento osmótico das sementes. Nessas metodologias, o mecanismo de ação pode estar relacionado com o "enfraquecimento" e "amolecimento" do endosperma, que possibilita o crescimento do embrião sob altas temperaturas (NASCIMENTO e CANTLIFFE, 2002).

Para Ferreira e Ranal (1999), a escarificação feita pelo hipoclorito de sódio evita a termodormência de sementes, pois, além de aumentar a permeabilidade do tegumento ao oxigênio, água e solutos, também pode facilitar a remoção ou oxidação de inibidores de germinação. Assim, o hipoclorito de sódio, em virtude da concentração e do tempo de exposição das sementes, pode funcionar como um promotor da germinação e da quebra de dormência (HISIAO et al.,1981). Logo, segundo os autores, essa técnica pode ser utilizada para quebra de dormência em sementes

Entretanto, Carnelossiet al. (1995) reiteram que o uso do hipoclorito de sódio pode afetar a germinação, havendo estímulo em algumas espécies, porém, em tratamentos prolongados, a germinação das sementes é reduzida.

Para Marcos Filho e Novembre (2009), a conceituação de "qualidade de sementes" tem se modificado à medida que o conhecimento sobre o assunto vem progredindo. Os autores ressaltam a importância da ação de um conjunto de características para determinar o nível de desempenho de um lote de sementes. Dessa forma, a expressão "qualidade de sementes" deve ser empregada para refletir o valor global de um lote de sementes, com o intuito de atender o principal objetivo de sua utilização que é o estabelecimento de um estande de produção.

Segundo Brasil (2009), a realização do teste de germinação em condições de campo não é geralmente satisfatória, pois, dada a variação das condições ambientais, os resultados nem sempre podem ser fielmente reproduzidos. Apesar dessa recomendação, este trabalho teve por objetivo avaliar, em condições de casa de vegetação e em altas temperaturas, e após a embebição em solução de hipoclorito de sódio, a germinação de sementes de sete cultivares de alface normalmente comercializadas em Parnaíba-PI.

\section{MATERIAL E MÉTODOS}

O ensaio foi desenvolvido durante o período de julho a agosto de 2013, na Embrapa Meio-Norte, UEP Parnaíba, (03ㅇำ $\mathrm{S} ; 41^{\circ} 46^{\prime} \mathrm{W}$ e $46,8 \mathrm{~m}$ de altitude). O clima da região é do tipo $\mathrm{C}_{1} \mathrm{dA}$ 'a' (THORNTHWAITE e MATHER, 1955), caracterizado como subúmido seco, megatérmico, com pequeno excedente hídrico e uma concentração de $29,7 \%$ da evapotranspiração potencial no trimestre outubro, novembro e dezembro, com umidade média relativa do ar de $77,5 \%$, precipitação média de $1107 \mathrm{~mm}$, e temperatura média de $27,6^{\circ} \mathrm{C}$ (BASTOS et al., 2012).

As sementes de alface utilizadas nesse ensaio foram adquiridas em lojas especializadas de venda de material agropecuário no município de Parnaíba-PI.

O delineamento experimental foi em blocos casualisados, com os tratamentos dispostos em arranjo fatorial 2 x 7 (duas variáveis como pré-germinativos: com imersão em $\mathrm{NaClO}$ e sem imersão em $\mathrm{NaClO}$, e sete cultivares de alface), com quatro repetições. As cultivares de alface foram adquiridas em lojas especializadas do município de ParnaíbaPI, em recipientes apropriados e contendo referências importantes como germinação (acima de 80\%), pureza e validade. 
As amostras de sementes que receberam tratamento pré-germinativo foram imersas em solução de $\mathrm{NaClO}$ a $1 \%$, por 3 minutos, e em seguida lavadas em água corrente. Após esse primeiro procedimento, as sementes foram secas em papel toalha e semeadas em bandejas de poliestireno expandido, com 128 células. Para cada tratamento, foi utilizado $1 / 4$ da bandeja de isopor, totalizando 32 células. Para preenchimento das bandejas foi utilizado substrato orgânico produzido localmente, constituído de uma mistura de palhadas vegetais e esterco bovino curtido. Após o semeio das sementes de alface, as bandejas foram levadas para a casa de vegetação. As bandejas semeadas foram irrigadas diariamente, mantendo-se a umidade desejada durante todo o período em que permaneceram na casa de vegetação.

Foram analisadas as seguintes variáveis: Primeira contagem do teste de germinação (PCG); Teste de germinação (TG) e Índice de velocidade de germinação (IVG). Na Primeira contagem do teste de germinação (PCG) foi registrado o porcentual de plântulas normais após quatro dias da implantação do teste de germinação (Brasil, 2009). Consideraram-se plântulas normais as que apresentaram todas as suas estruturas essenciais perfeitas. No teste de germinação (TG) as plântulas normais foram registradas aos sete e 14 dias e os resultados expressos em porcentagem. Para o Índice de velocidade de germinação (IVG) foi registrado o número de plântulas normais até os sete dias. Para o cálculo, foi utilizada a fórmula proposta por Maguire (1962), em que: $\mathrm{IVG}=\mathrm{G} 1 / \mathrm{D} 1+\mathrm{G} 2 / \mathrm{D} 2+. . \mathrm{Gn} / \mathrm{Dn}$, onde $\mathrm{IVG}=$ Índice de Velocidade de Germinação; G1, G2,.., Gn= ${ }^{\circ}$ de radículas emergidas, observadas no

da $1^{\mathrm{a}}, 2^{\mathrm{a}}, .$. , última contagem; D1, D2, .., Dn $=\mathrm{n}^{\mathrm{o}}$ de

dias de semeadura à $1^{\mathrm{a}}, 2^{\mathrm{a}}, . .$, última contagem.

Os dados obtidos foram tabulados e submetidos à análise da variância, utilizando-se o software "ASSISTAT" para medir a significância da variação não ocasional dos valores e o teste de Tukey, ao nível de 5\% de probabilidade, para o contraste das médias.

\section{RESULTADOS E DISCUSSÃO}

No teste de primeira contagem (Tabela 1), houve diferenças significativas para os lotes que receberam tratamento pré-germinativo com o hipoclorito de sódio, com destaque para a cultivar T6, que obteve $84,41 \%$ de plântulas quatro dias após a semeadura. Todas as cultivares que receberam tratamento pré-germinativo obtiveram resultados expressivos, quando comparadas às que não receberam este tratamento, destacando-se as cultivares T1, T4 e T7, com acréscimos de $40,62 \%, 30,12 \%$ e $27,08 \%$, respectivamente de PCG.

Tabela 1 - Primeira Contagem de Germinação: Influência do $\mathrm{NaClO}$ na germinação da semente de alface (\% de plântulas quatro dias após a semeadura). Parnaíba-PI, 2013.

\begin{tabular}{cccccccccc}
\hline & \multicolumn{9}{c}{ Cultivares } \\
\cline { 2 - 10 } $\mathrm{NaCl}$ & $\mathrm{T} 1$ & $\mathrm{~T} 2$ & $\mathrm{~T} 3$ & $\mathrm{~T} 4$ & $\mathrm{~T} 5$ & $\mathrm{~T} 6$ & $\mathrm{~T} 7$ & Média & CV \\
\hline Com & 56,24 & 4,16 & 4,16 & 48,86 & 36,44 & 84,41 & 31,24 & $37,64^{\mathrm{a}}$ \\
Sem & 15,62 & 3,25 & 0,00 & 18,74 & 13,53 & 66,66 & 4,16 & $17,42^{\mathrm{b}}$ & \\
\hline Média & $35,93^{\mathrm{b}}$ & $3,70^{\mathrm{c}}$ & $2,08^{\mathrm{c}}$ & $32,80^{\mathrm{b}}$ & $24,98^{\mathrm{b}}$ & $75,53^{\mathrm{a}}$ & $17,70^{\mathrm{bc}}$ & & 47,15 \\
\hline
\end{tabular}

Nas colunas, médias seguidas de letras iguais não diferem $(\mathrm{P}>0,05)$ pelo teste de Tukey.

Rodrigues et al. (2012), em seu trabalho com tratamento pré-germinativo em sementes de alface, observaram que o vigor representado pela primeira contagem do teste de germinação foi superior nas sementes osmocondicionadas e a utilização de $\mathrm{NaClO}$ aumentou a porcentagem de germinação.

De acordo com Nascimento e Pereira (2007), o teste de primeira contagem, geralmente tem sido utilizado como um teste de vigor, devido à sua simplicidade e por ser conduzido juntamente com o teste de germinação. Os mesmos autores concluem que este teste pode ser utilizado como parâmetro para a melhor escolha dos lotes de sementes de alface para as condições de semeadura sob altas temperaturas.
Na Tabela 2 encontram-se os dados obtidos nos testes de índice de velocidade de germinação de sete cultivares de alface. A maior velocidade de germinação observada foi para a cultivar T6 independente da ausência ou presença do tratamento pré-germinativo. As sementes tratadas com $\mathrm{NaClO}$, para esta cultivar, obtiveram $85,41 \%$ de plântulas após sete dias da semeadura, evidenciando o seu melhor vigor. Também a maioria das cultivares que receberam tratamento pré-germinativo obteve resultados diferentes daquelas com ausência deste método, destacandose a cultivar T7 que, ao receber o tratamento, obteve $40,61 \%$ de IVG.

Tabela 2 - Índice de Velocidade de Germinação: Influência do $\mathrm{NaClO}$ na germinação da semente de alface (\% de plântulas sete dias após a semeadura). Parnaíba-PI, 2013.

\begin{tabular}{|c|c|c|c|c|c|c|c|c|}
\hline \multirow[b]{2}{*}{$\mathrm{NaCl}$} & \multicolumn{5}{|c|}{ Cultivares } & \multirow[b]{2}{*}{ T6 } & \multirow[b]{2}{*}{$\mathrm{T} 7$} & \multirow[b]{2}{*}{$\mathrm{CV}$} \\
\hline & $\mathrm{T} 1$ & $\mathrm{~T} 2$ & T3 & $\mathrm{T} 4$ & T5 & & & \\
\hline Com & $63,53^{\mathrm{aB}}$ & $18,74^{\mathrm{aD}}$ & $9,37^{\mathrm{aD}}$ & $70,83^{\mathrm{aAB}}$ & $38,54^{\mathrm{aC}}$ & $85,41^{\mathrm{aA}}$ & $40,61^{\mathrm{aC}}$ & 20,83 \\
\hline Sem & $33,33^{\mathrm{bC}}$ & $6,24^{\mathrm{bD}}$ & $0,00^{\mathrm{aD}}$ & $51,03^{\mathrm{bB}}$ & $30,20^{\mathrm{aC}}$ & $79,16^{\mathrm{aA}}$ & $8,33^{\mathrm{bD}}$ & \\
\hline Média & 48,43 & 12,49 & 4,68 & 60,93 & 34,37 & 82,28 & 24,47 & 20,83 \\
\hline
\end{tabular}

Médias seguidas de letras iguais, minúsculas nas colunas e maiúsculas nas linhas, não diferem $(\mathrm{P}>0,05)$ pelo teste de Tukey.

Rodrigues et al. (2012) obtiveram os melhores resultados para IVG em sementes que receberam tratamentos de hidrocondicionamento em papel e hidrocondicionamento por imersão em água destilada sem a imersão em solução de
$\mathrm{NaClO}$ e em sementes osmocondicionadas em solução de $\mathrm{NaClO}$. Os mesmos autores concluíram que a imersão de sementes em solução de $\mathrm{NaClO}$ favoreceu somente os resultados das sementes osmocondicionadas. 
De acordo com Nascimento (2003), a velocidade de germinação pode ser utilizada para identificar lotes de sementes com emergência mais rápida em campo ou em estufa, minimizando assim as condições adversas que ocorrem durante a germinação e estabelecimento de plântulas. Segundo o referido autor, no cultivo da alface, isso é muito importante, pois sob altas temperaturas, principalmente durante as primeiras horas de germinação, pode ocorrer a termoinibição e/ou a termodormência das sementes, afetando assim o estabelecimento da cultura. Dados meteorológicos diários (Figura 1) referentes à época de realização deste ensaio registrou média máxima de até $35,3^{\circ} \mathrm{C}$.

Figura 1 - Médias de temperatura em Parnaíba-PI. 2013

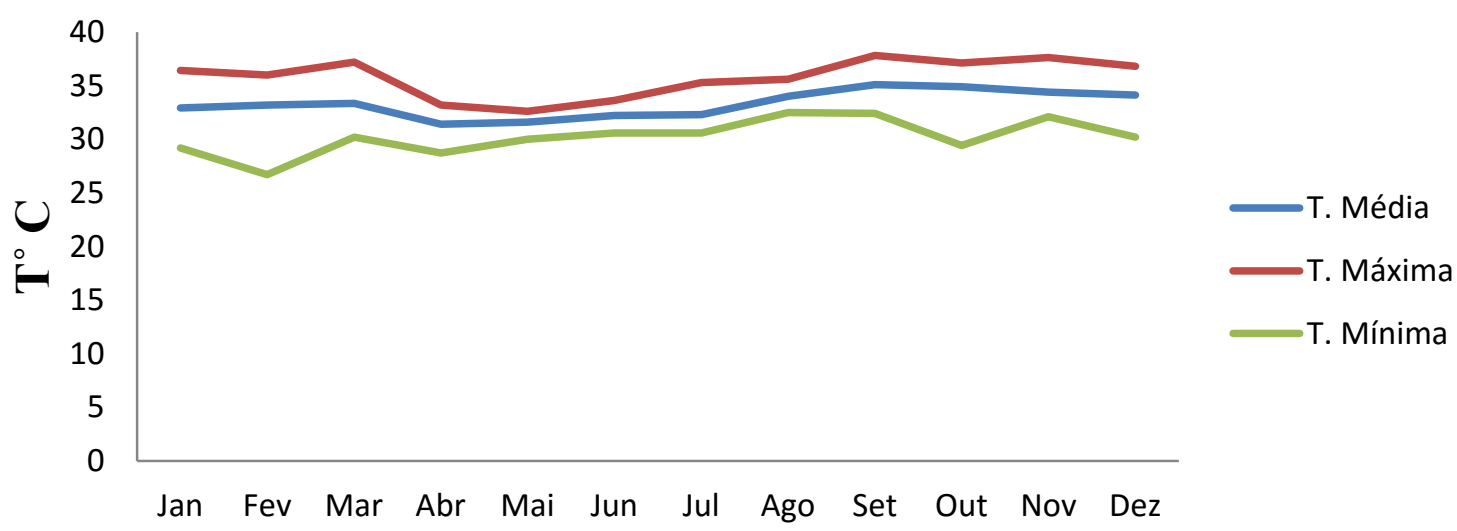

De acordo com Nascimento e Pereira (2007), a avaliação da qualidade fisiológica de sementes para fins de semeadura e comercialização tem sido rotineiramente baseada

no teste de germinação. Na Tabela 3 encontram-se os dados obtidos nos testes de germinação de sete cultivares de alface.

Tabela 3 - Teste de Germinação: Influência do $\mathrm{NaClO}$ na germinação da semente de alface (número de plântulas sete dias após a semeadura). Parnaíba-PI, 2013.

\begin{tabular}{|c|c|c|c|c|c|c|c|c|}
\hline \multirow[b]{2}{*}{$\mathrm{NaCl}$} & \multicolumn{7}{|c|}{ Cultivares } & \multirow[b]{2}{*}{$\mathrm{CV}$} \\
\hline & $\mathrm{T} 1$ & $\mathrm{~T} 2$ & T3 & $\mathrm{T} 4$ & T5 & T6 & $\mathrm{T} 7$ & \\
\hline Com & $15,25^{\mathrm{aB}}$ & $4,75^{\mathrm{aD}}$ & $2,75^{\mathrm{aD}}$ & $17,25^{\mathrm{aC}}$ & $10,25^{\mathrm{aC}}$ & $20,00^{\mathrm{aA}}$ & $10,00^{\mathrm{aC}}$ & \\
\hline Sem & $7,50^{\mathrm{bC}}$ & $2,0^{\mathrm{bD}}$ & $0,75^{\mathrm{aD}}$ & $13,00^{\mathrm{bB}}$ & $7,75^{\mathrm{aC}}$ & $19,00^{\mathrm{aA}}$ & $2,75^{\mathrm{bD}}$ & \\
\hline Média & 11,37 & 3,37 & 1,75 & 15,12 & 9,00 & 19,5 & 6,37 & 19,07 \\
\hline
\end{tabular}

Médias seguidas de letras iguais, minúsculas nas colunas e maiúsculas nas linhas, não diferem $(\mathrm{P}>0,05)$ pelo teste de Tukey.

Houve diferenças significativas entre os lotes de sementes. Independente da presença ou ausência do tratamento pré-germinativo, a cultivar T6 foi a que apresentou os melhores resultados, chegando a registrar de $86 \%$ a $96 \%$, em relação a cultivar T3, evidenciando dessa forma o maior vigor da cultivar em relação às demais. Entretanto, a germinação de todos os lotes foi inferior ao estabelecido para comercialização de sementes de alface $(80 \%)$, tendo a cultivar T6, apresentando os melhores resultados com tratamento prégerminativo, obtendo um pouco mais de $62 \%$ de germinação.

A maioria das cultivares que receberam tratamento pré-germinativo obteve resultados diferentes daquelas com ausência deste método, destacando-se a cultivar T7 que teve um incremento superior a $72 \%$. Esses resultados não podem ser atribuídos à qualidade inicial das sementes, visto que todas as cultivares foram adquiridas em lojas especializadas de Parnaíba-PI, em recipientes apropriados e contendo referências importantes como germinação (acima de 80\%), pureza e validade.

Franzinet al. (2004), em seu trabalho de avaliação do vigor de sementes de alface nuas e peletizadas, observaram que houve estratificação dos lotes na germinação e no vigor, atribuindo tais resultados às influências da peletização e/ou métodos utilizados para avaliar essas sementes. Os resultados obtidos neste estudo, sob as condições edafoclimáticas de Parnaíba, região norte do Estado do Piauí, reforçam a necessidade de escolha de testes mais eficientes para a avaliação de sementes de alface, entretanto, podem servir como parâmetro na escolha de cultivares que tenham um melhor desempenho sob temperaturas adversas.

\section{CONCLUSÕES}

Independente da presença ou ausência do tratamento pré-germinativo, a cultivar T6 foi a que apresentou os melhores resultados.

Todas as cultivares que receberam tratamento com o hipoclorito de sódio ( $\mathrm{NaClO})$ obtiveram resultados expressivos, quando comparadas às que não receberam esse tratamento, entretanto, a germinação de todos os lotes de sementes foi inferior ao estabelecido para comercialização de sementes de alface, com recomendações de acima de $80 \%$.

\section{REFERÊNCIAS BIBLIOGRÁFICAS}

BERTAGNOLLI, C. M.; MENEZES, N. L.; STORK, L.; SANTOS, O. S.; PASQUALLI, L. L. Desempenho de sementes nuas e peletizadas de alface (Lactuca sativa L.) submetidas a estresses hídrico e térmico. Revista Brasileira de Sementes, Londrina, v. 25, n. 1, p. 7-13, 2003.

BRASIL. Regras para análise de sementes. Brasília, DF: Mapa/ACS. 398p. 2009. 
BASTOS, E. A.; ANDRADE JUNIOR, A. S. de; RODRIGUES, B. H. N. Boletim agrometeorológico de 2011 para o município de Parnaíba, Piauí. Teresina: Embrapa Meio-Norte, 2012. 37p. (Embrapa Meio-Norte. Documentos, 221).

CARNELOSSI, M. A. G.; LAMOUNIER, L.; RANAL, M. A. Efeito da luz, hipoclorito de sódio, escarificação e estratificação na germinação de sementes de alface (Lactuca sativa L.) cv. Maioba e moreninha-deuberlândia. Pesquisa Agropecuária Brasileira, v.30, n.6, p.779-787, 1995.

FERREIRA, W.R.; RANAL, M.A. Germinação de sementes e crescimento de plântulas de Brassicachinensis L. var.Parachinensis (Bailey) Sinskaja (couve-da-malásia). Pesquisa Agropecuária Brasileira, v.34, n.3, p.353361, 1999.

FILGUEIRA, F. A. R. Novo manual de olericultura: agrotecnologia moderna na produção e comercialização de hortaliças.Viçosa,Editora UFV. 2 ed. 412p. 2003.

FRANZIN, S. M.; MENEZES, N. L. de; GARCIA, D. C.; ROVERSI, T. Avaliação do vigor de sementes de alface nuas e peletizadas. RevistaBrasileira de Sementes, v.26, n.2, p.114-118, 2004.

HISIAO, A.I.; WORSHAM, A.D.; MORELAND, D.E. Effects of sodium hypochlorite and certain plant growth regulators on germination of witchweed (Strigaasiatica) seeds.Weed Science, Champaign, v.29, n.1, p. 98-100, 1981.

MAGUIRE, J.D. Speed of germination-aid in selection and evaluation for seedlig emergence and vigor. Madison, Crop Science, v.2, n.1, p.176-177,1962.

MARCOS FILHO, J. Fisiologia de sementes de plantas cultivadas. Piracicaba: FEALQ, 495p. 2005.

MARCOS FILHO, J.; NOVEMBRE, A.D.L.C. Avaliação do potencial fisiológico de sementes de hortaliças. In: NASCIMENTO, W.M. (Ed.). Tecnologia de sementes de hortaliças. Brasília, DF: Embrapa Hortaliças, 2009. p.185-246.

MINISTÉRIO DA AGRICULTURA. Dados socioeconômicos da cadeia produtiva de hortaliças. Disponível http://www.agricultura.gov.br/arq_editor/file/camaras_se toriais/Hortalicas/Dados_Economicos/ABCSEM\%20201 1.pdf. Acesso 28set2015.

NASCIMENTO, W. M.; CANTLIFFE, D. J. Germinação de sementes de alface sob altas temperaturas. HorticulturaBrasileira, v.20, n.1, p.103-106, 2002.

NASCIMENTO, W. M. Preventing thermoinhibition in a thermosensitive lettuce genotype by seed imbibition at low temperature.ScientiaAgricola, v.60, n.3, p.477-480, 2003.

NASCIMENTO, W. M.; PEREIRA, R. S. Testes para avaliação do potencial fisiológico de sementes de alface e sua relação com a germinação sob temperaturas adversas. Revista Brasileira de Sementes, v.29, n.3, p.175-179, 2007.

QUEIROGA, R.C.F.; BEZERRA NETO, F.; NEGREIROS, M.Z.; OLIVEIRA, A.P.; AZEVEDO, C.M.S.B. Produção de alface em função de cultivares e tipos de tela de sombreamento nas condições de Mossoró. Horticultura Brasileira, Brasília, v. 19, n. 3, p. 192196, novembro 2.001.

RESENDE, F. V.; SAMINÊS, T. C. O.; VIDAL, M. C.; SOUZA, R. B.; CLEMENTE, F. M. V. Cultivo de alface em sistema orgânico de produção. Embrapa Hortaliças, 2007, 16p. (Embrapa Hortaliças, Circular Técnica, 56).

RODRIGUES, D. L.; LOPES, H. M.; SILVA, E. R. da; MENEZES, B. R. da S. Embebição, condicionamento fisiológico e efeito do hipoclorito de sódio na germinação de sementes de alface. Revista Trópica Ciências Agrárias e Biológicas, v.6, n.1, p.52-61, 2012.

SILVA, A. C. F.; VIZZOTTO, V. J. Avaliação de cultivares de alface no verão para o Litoral Catarinense. AgropecuáriaCatarinense, n.7, p.23-27, 1994.

SETÚBAL， W.J.; SILVA, A R. Avaliação do comportamento de alface de verão em condições de calor no município de Teresina/PI. Teresina, UFPI, 1992. 17 p. (Mimeografado).

THORNTHWAITE, C. W.; MATHER, J. R.The water balance.Centerton: Drexel Institute of technology, 1955. 104 p. (Drexel Institute of technology.Publication in climatology, v. 8, n. 1). 